Prepared in cooperation with the National Park Service

\title{
Weather and Climate Monitoring Protocol, Channel Islands National Park, California
}

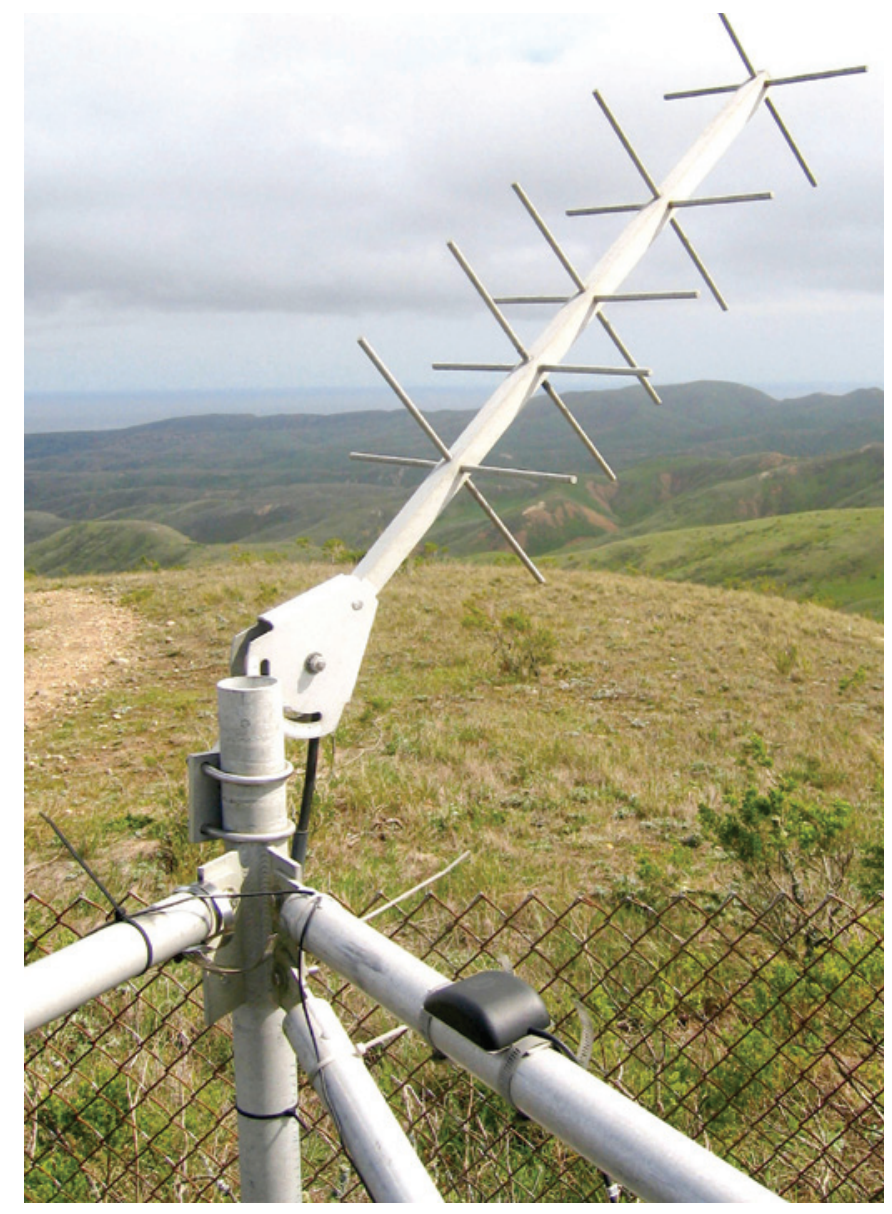

Techniques and Methods 2-B1 
Cover photo caption:

Santa Rosa Island, Channel Islands National Park Remote Automated Weather Station antenna, view to North. Photograph by Rockne Rudolph, National Park Service, 2006. 


\section{Weather and Climate Monitoring Protocol, Channel Islands National Park, California}

By Kathryn McEachern, Paula Power, Linda Dye, and Rocky Rudolph

Chapter 1 of

Section B, Climatological Science

Book 2, Collection of Environmental Data

Prepared in cooperation with the National Park Service

Techniques and Methods 2-B1

U.S. Department of the Interior

U.S. Geological Survey 


\section{U.S. Department of the Interior DIRK KEMPTHORNE, Secretary}

\section{U.S. Geological Survey \\ Mark D. Myers, Director}

\section{U.S. Geological Survey, Reston, Virginia: 2008}

For product and ordering information:

World Wide Web: http://www.usgs.gov/pubprod

Telephone: 1-888-ASK-USGS

For more information on the USGS--the Federal source for science about the Earth, its natural and living resources, natural hazards, and the environment:

World Wide Web: http://www.usgs.gov

Telephone: 1-888-ASK-USGS

Any use of trade, product, or firm names is for descriptive purposes only and does not imply endorsement by the U.S. Government.

Although this report is in the public domain, permission must be secured from the individual copyright owners to reproduce any copyrighted materials contained within this report.

Suggested citation:

McEachern, Kathryn; Power, Paula; Dye, Linda; and Rudolph, Rocky, 2008, Weather and climate monitoring protocol, Channel Islands National Park, California: U.S. Geological Survey Techniques and Methods 2-B1, 16 p. Available at http://pubs.usgs.gov/tm/tm2b1/ 


\section{Contents}

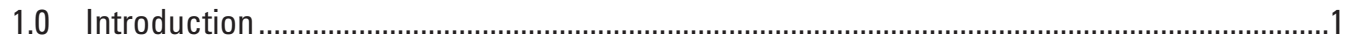

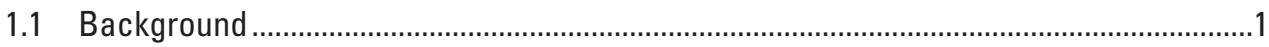

1.2 Objectives of Weather and Climate Monitoring …………….............................................

2.0 Island Weather Stations ………..........................................................................................

2.1 Anacapa Island Overview..........................................................................................

National Park Service Remote Automated Weather Station .............................................4

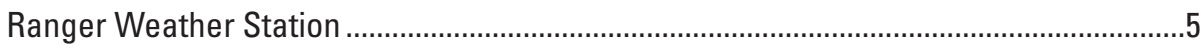

2.2 Santa Cruz Island Overview ......................................................................................

National Park Service Remote Automated Weather Station - Main Ranch .....................6

Weather Stations Operated by Others .............................................................................

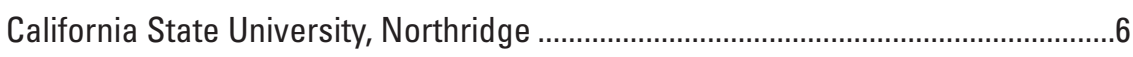

Santa Barbara Amateur Radio Club - Diablo Peak...................................................

University of California, Santa Barbara ................................................................

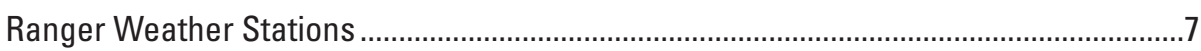

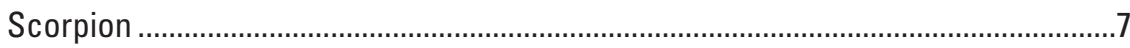

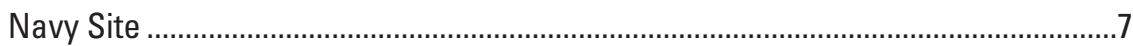

Main Ranch Precipitation Data ..............................................................................

2.3 Santa Rosa Island Overview ........................................................................................

National Park Service Remote Automated Weather Station—Black Mountain ..............8

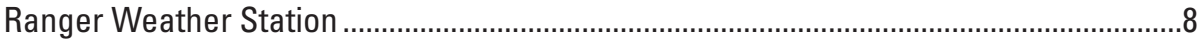

2.4 Santa Barbara Island Overview.....................................................................................

National Park Service Remote Automated Weather Station ............................................9

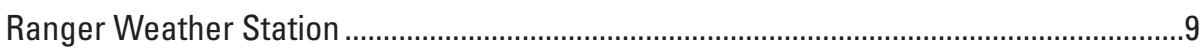

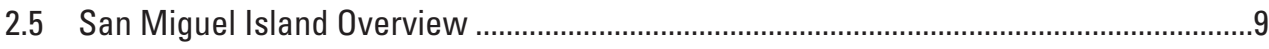

National Park Service Remote Automated Weather Station ...............................................

Remote Automated Weather Station Operated by the Navy.............................................10

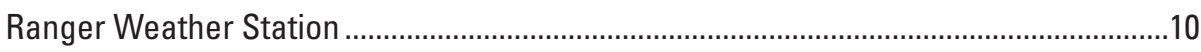

3.0 Weather Station Maintenance and Diagnostics ....................................................................11

3.1 Remote Automated Weather Station (RAWS) Maintenance ..........................................11

3.2 Ranger Weather Station Instrument Maintenance .......................................................11

4.0 Weather and Climate Monitoring Program Tasks and Roles .................................................11

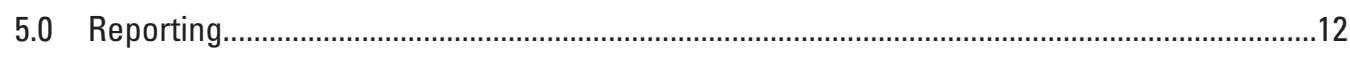

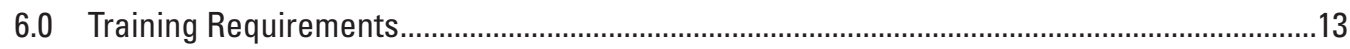

7.0 Channel Islands National Park Weather Data Websites.........................................................13

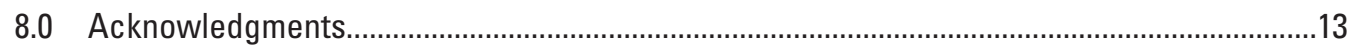

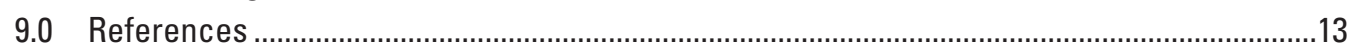

Appendix A. Channel Islands National Park Remote Automated Weather Stations ...................14

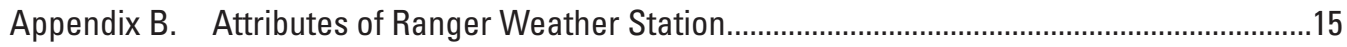




\section{Figures}

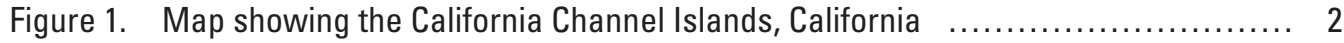

Figure 2. Map showing location of the Remote Automated Weather Stations (RAWS)

and Ranger Weather Station on Anacapa Island, Channel Island National Park, California

4

Figure 3. Map showing location of seven Remote Automated Weather Stations (RAWS) and two Ranger Weather Stations on Santa Cruz Island, Channel Island National Park, California

Figure 4. Map showing location of one Remote Automated Weather Station (RAWS) and current and historic Ranger Weather Stations on Santa Rosa Island, Channel Island National Park, California

Figure 5. Map showing location of one Remote Automated Weather Station (RAWS) and a Ranger Weather Station on Santa Barbara Island, Channel Islands National Park, California

Figure 6. Map showing location of a Remote Automated Weather Station (RAWS) and a Ranger Weather Station on San Miguel Island, Channel Islands National Park, California

\section{Tables}

Table 1. Automated Remote Weather Stations operated by other agencies or organizations on Santa Cruz Island and San Miguel Islands, Channel Islands National Park, California

Table 2. Websites with data from Remote Automated Weather Stations located in Channel Islands National Park, California 12

Appendix A. Channel Islands National Park Remote Automated Weather Stations 14

Appendix B. Attributes of Ranger Stations Weather Stations on the Channel Islands, California 


\title{
Weather and Climate Monitoring Protocol, Channel Islands National Park, California
}

\author{
By Kathryn McEachern', Paula Power', Linda Dye', and Rocky Rudolph²
}

\subsection{Introduction}

Weather and climate are strong drivers of population dynamics, plant and animal spatial distributions, community interactions, and ecosystem states. Information on local weather and climate is crucial in interpreting trends and patterns in the natural environment for resource management, research, and visitor enjoyment. This document describes the weather and climate monitoring program at the Channel Islands National Park (fig. 1), initiated in the 1990s. Manual and automated stations, which continue to evolve as technology changes, are being used for this program. The document reviews the history of weather data collection on each of the five Channel Islands National Park islands, presents program administrative structure, and provides an overview of procedures for data collection, archival, retrieval, and reporting. This program overview is accompanied by the "Channel Islands National Park Remote Automated Weather Station Field Handbook" and the "Channel Islands National Park Ranger Weather Station Field Handbook." These Handbooks are maintained separately at the Channel Island National Park as "live documents" that are updated as needed to provide a current working manual of weather and climate monitoring procedures. They are available on request from the Weather Program Manager (Channel Islands National Park, 1901 Spinnaker Dr., Ventura, CA 93001; 805.658.5700). The two Field Handbooks describe in detail protocols for managing the four remote automated weather stations (RAWS) and the seven manual Ranger Weather Stations on the islands, including standard operating procedures for equipment maintenance and calibration; manufacturer operating manuals; data retrieval and archiving; metada collection and archival; and local, agency, and vendor contracts.

\subsection{Background}

Channel Islands National Park includes the northernmost five of the eight offshore California Channel Islands, scattered from near Point Conception, California, USA, to the border

${ }^{1}$ U.S. Geological Survey, Western Ecological Research Center, Channel Islands Field Station.

${ }^{2}$ National Park Service, Channel Islands National Park. with Mexico (fig. 1). The Park islands lie 20 to 61 kilometers (12 to 38 miles) offshore in the Pacific Ocean. They span a major transition in climate that begins at the California coastline where the cool waters of the northern Humboldt Current mix with the warmer waters of the California Current from the south (Redmond and McCurdy, 2005). The Santa Barbara Channel separates the northern four islands from the mainland and the San Pedro Channel separates the southern islands from mainland California. Both channels are major shipping lanes for commercial and recreational traffic traveling north and south along the California coastline.

The five Park islands include Anacapa Island (AI), Santa Cruz Island (SCI), Santa Rosa Island (SRI), and San Miguel Island (SMI) in the northern island group and Santa Barbara Island (SBI) in the southern group. Ownership of the islands varied in the past, ranging from private ranchers to government agencies. Anacapa, San Miguel, and Santa Barbara Islands, administered by the Department of Defense, were transferred to the National Park Service and designated as the Channel Islands National Monument in 1938 and re-dedicated as Channel Islands National Park in 1980. Santa Rosa Island was purchased from private owners in 1986 . The eastern 10 percent of Santa Cruz Island was transferred to the Channel Islands National Park in 1997, and another 14 percent was deeded to the NPS by The Nature Conservancy in 2000. All five islands are currently administered by the National Park Service, although ownership is still shared with others in several instances. For example, the U.S. Coast Guard owns the East Anacapa lighthouse and surrounding 65 hectares (161 acres), the U.S. Navy owns San Miguel Island, and The Nature Conservancy owns the western 76 percent of Santa Cruz Island. The history of weather data collection for the islands varies with the ownership history. Weather records, primarily precipitation, were kept by some ranchers and government agencies; thus records extend back to the early 1900s for some of the islands. Until development of the long-term weather monitoring program by the NPS in the mid-1980s, there was little consistency among the islands in how weather was measured and recorded (Richards, 1997). 


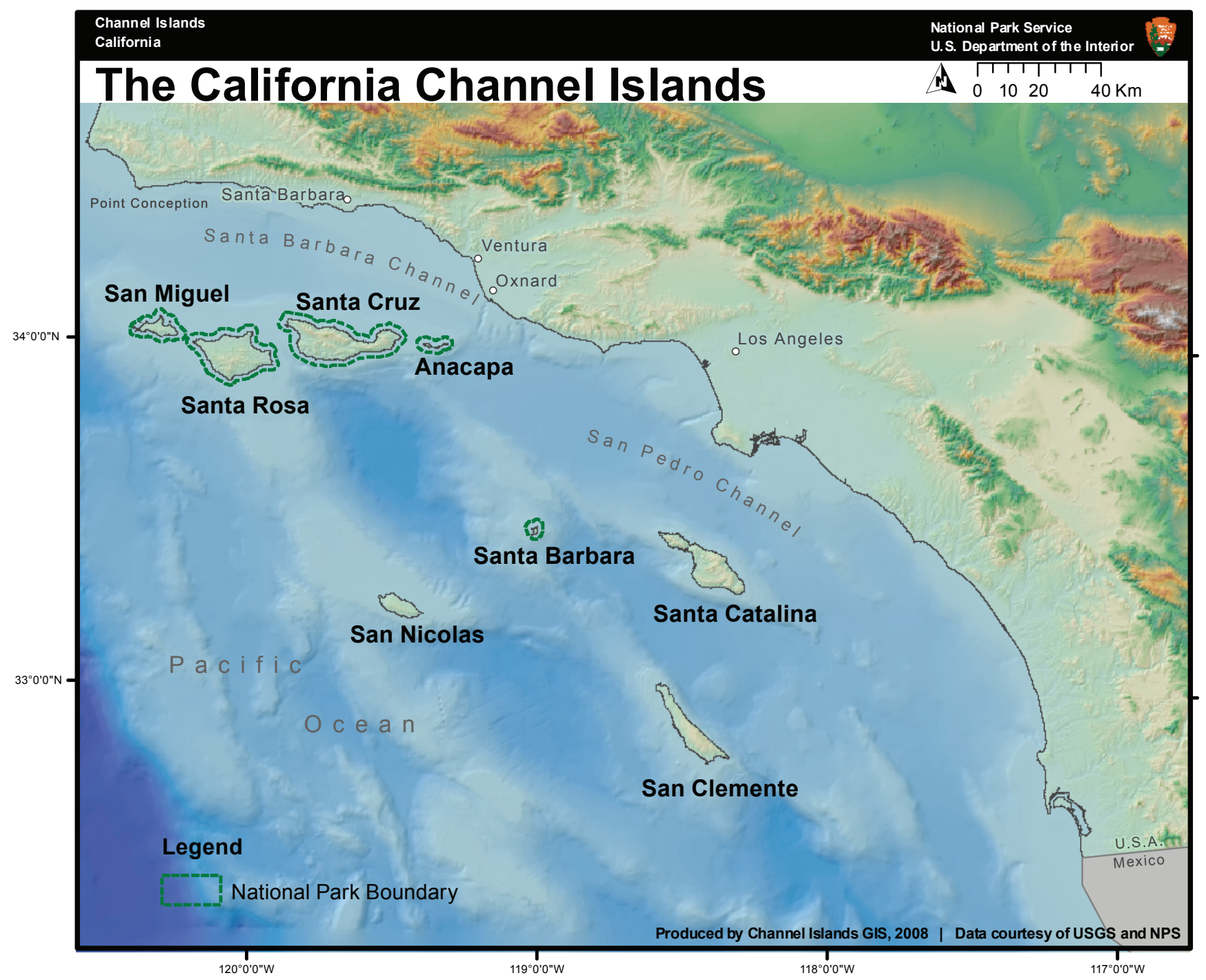

Figure 1. The California Channel Islands, California.

For the weather monitoring program, Remote Automated Weather Stations (RAWS) were established on four of the islands; no RAWS was established on San Miguel Island. Daily measurements are made at six additional sites by Park staff when they are on the islands (Ranger Weather Station data). These measurements supplement the RAWS data. The RAWS data are downloaded via satellite and archived by the Western Regional Climate Center (WRCC) at the Desert Research Institute in Reno, Nevada. The WRCC also archives the Ranger Weather Station data for the Park. The weather data are available through the WRCC website at http://www. wrcc.dri.edu/channel isl. The RAWS parameters measured include precipitation, air temperature, relative humidity, wind speed and direction, solar radiation, fuel moisture, fuel temperature, and barometric pressure.

Redmond and McCurdy (2005) discuss an approach to weather and climate monitoring among the Channel Islands in the context of nationwide climate monitoring and modeling. Their rationale and specific design considerations form the basis for the Channel Islands National Park weather and climate monitoring program, including the choices of parameters to measure, RAWS and Ranger Weather Station site selection, considerations for data handling and display, and operating procedures for site maintenance. The Channel Islands National Park Weather and Climate Monitoring Program builds upon their recommendations. This program protocol document presents an overview of weather data collected on each island, including historic and current station locations, historic data available, equipment used and maintenance schedules, procedures for data handling and display, general staffing and training requirements, annual reporting, and program administration. Two additional standalone Field Handbooks presenting operational details on station equipment, manufacturer manuals, equipment technical support, and station maintenance for the RAWS and Ranger Weather Stations are available from the Weather Program Manager at Channel Islands National Park. It is anticipated that this protocol document and the two Field Handbooks will require updating as technology changes; the updates will be logged and tracked independently for this protocol document 
and each Handbook. Operational changes will be incorporated into the Weather and Climate Monitoring Program documents as they are made, rather than being compiled annually into a single Program report. In this way, operations staff will always have current guidelines and contacts for procedures and protocols essential for efficient and continuous data collection and archival.

\subsection{Objectives of Weather and Climate Monitoring}

The Channel Islands National Park maintains long-term monitoring of terrestrial and marine flora and fauna, along with visitor-use statistics and interpretive education programs. The relative year-to-year variation in winter precipitation is greater along the California coast between Los Angeles and San Diego than anywhere else in the United States (Yoho and others, 1999; Redmond and McCurdy, 2005). In the Mediterranean climate of this region, weather patterns influence plant and animal abundance, and climate often explains the annual patterns and long-term trends seen in the monitoring data. Climate also influences the distributions of plants and animals across the islands, and it forms the context for the development of the unique island ecosystems protected by the Park. Evidence is accumulating that California's climate is changing. A major unresolved regional question is whether variations in California's rich marine upwelling systems track variations in the mainland's climate. Owing to its extensive monitoring program and offshore location, the Channel Islands National Park is well suited to address such local, regional, and globally important questions with weather and other monitoring data.

It is crucial that the weather monitoring program be conducted in a consistent manner through time to provide a continuous and reliable record of weather and climate across all of the islands. Weather monitoring includes data acquisition and storage, reporting, and careful documentation of station locations, maintenance, and performance through time. This protocol provides guidelines for consistent, long-term weather monitoring for use by the National Park Service (NPS) and others.

The objectives of the Weather and Climate Monitoring Program at the Channel Islands National Park and protocol follow:

- Provide the Channel Islands National Park with hourly and daily data on precipitation, air temperature, wind direction and speed, solar radiation, fuel moisture and fuel temperature, barometric pressure, and dew point. Data are digitally accessible via the Internet in nearreal time for a variety of users, including Park staff, cooperators, visitors, and the public.

- Provide weather and climate data for a variety of uses, such as early warnings of potential hazards to both marine and terrestrial systems, for mariner safety, for fire planning and management, for visitor inquiries, and for climatic, physical and ecological research needs.

- Provide data for evaluation of climate patterns and long-term trends. Identify trends and patterns over periods of 5 to 100 years in surface temperatures, wind speed and direction, precipitation, and climate extremes on the five islands of the Channel Islands National Park.

\subsection{Island Weather Stations}

Of the five islands making up the Channel Island National Park, all but San Miguel have one or more Remote Automated Weather Stations (RAWS). Data from the RAWS are supplemented by data collected using weather instruments manually operated by island staff (Ranger Weather Station data). Collectively, the stations provide data on weather from both the marine layer and the terrestrial climate regimes of the islands. Redmond and McCurdy (2005) provide an analysis of considerations for siting weather stations in the context of local and regional climate analysis. In addition to the Park, a number of agencies and organizations have also invested in island weather stations, including the National Interagency Fire Center (NIFC); the U.S. Navy; the county of Santa Barbara; the California State University, Northridge (CSUN); the University of California, Santa Barbara; and the Santa Barbara Amateur Radio Club. Collectively, these stations address the needs of Channel Islands National Park operations and resource management, fire planning and management, Navy operations, mariner safety, and specific research needs. Although each station contributes to a holistic view of weather and climate across the islands, the Channel Islands National Park confines its monitoring program to those RAWS and Ranger Weather Stations owned and operated by the Park. The stations are discussed in this report, and the data are accessible through the WRCC website.

The following sections describe the history of the Park-managed RAWS and Ranger Weather Stations on each island, including placement of the stations, parts upgrades, maintenance schedules, and funding and maintenance responsibilities. Appendixes A and B list station locations, data collected, and types of sensors used for the RAWS and Ranger Weather Stations. In general, automated weather data collection began on the islands in the 1990s. NPS staff has recorded weather observations using various types of equipment since the early 1990s. Historic weather observations were made on most of the islands during the last century, however, those records vary in quality and consistency. The Park archives these records within the Weather and Climate Monitoring Program, but they are not included as part of the contemporary island weather record available on-line. 


\subsection{Anacapa Island Overview}

The Park operates one RAWS and one Ranger Weather Station on East Anacapa Island (fig. 2). The U.S. Coast Guard collected weather observations prior to National Park Service management of the island. However, those records are lost, and the earliest weather records date from the 1990s.

\section{National Park Service Remote Automated Weather Station}

The Anacapa Island weather program was developed in partnership with Santa Barbara County's Fisheries Enhancement Fund, which helps mitigate the adverse impacts of offshore oil development on local commercial fishing. The California Office of Historic Preservation, the Coast Guard, the National Weather Service, and commercial fishers supported the installation of a weather stations on East Anacapa Island. The weather station was funded by the county of Santa Barbara through a Memorandum of Agreement between the County and the Park (Agreement No. G8120020002). California State University, Northridge (CSUN), personnel installed the station in May 2004 (Appendix A).

The weather station was placed on the historic fog horn building to record unobstructed wind conditions, including Santa Ana winds. California's Office of Historic Preservation concurred with the Park's finding that placing weather instrumentation on a platform attached to the building would have no adverse effect on the historic building.

The Anacapa Island RAWS provides near real-time weather data for the east end of the Santa Barbara Channel, the most heavily traveled section of the channel. These data aid mariners by notifying them of potentially dangerous changes in wind conditions. The station also provides long-term climate data for resource management and fire planning.

The RAWS is mounted on the historic fog horn building at an elevation of 84 meters $(\mathrm{m})(277 \mathrm{feet}[\mathrm{ft}])$ above mean sea level, latitude $34^{\circ} 00^{\prime} 57^{\prime \prime}$, longitude $119^{\circ} 21^{\prime} 35^{\prime \prime}$. Because the weather station is mounted on the fog horn building, sensor cables are custom-made to specific lengths listed in the Channel Islands National Park Remote Automated Weather Station Field Handbook. Power is supplied with a 20-watt solar panel and auxiliary battery. The system is a Handar 555 . Sensors include wind speed/wind direction, precipitation, solar radiation, relative humidity/air temperature, and fuel moisture/fuel temperature. For a complete description of software and sensors on the Anacapa station see Appendix A. Data are transmitted through a Geostationary Operational Environmental Satellite (GOES) antenna to a satellite, where they are downloaded and posted on the WRCC website, in cooperation with NIFC. The data are recorded at 10-minute intervals and summarized by hour on the website. Scheduled maintenance of the RAWS consists of an annual sensor and an as-needed cable swap required because the harsh environment quickly corrodes weather station parts.

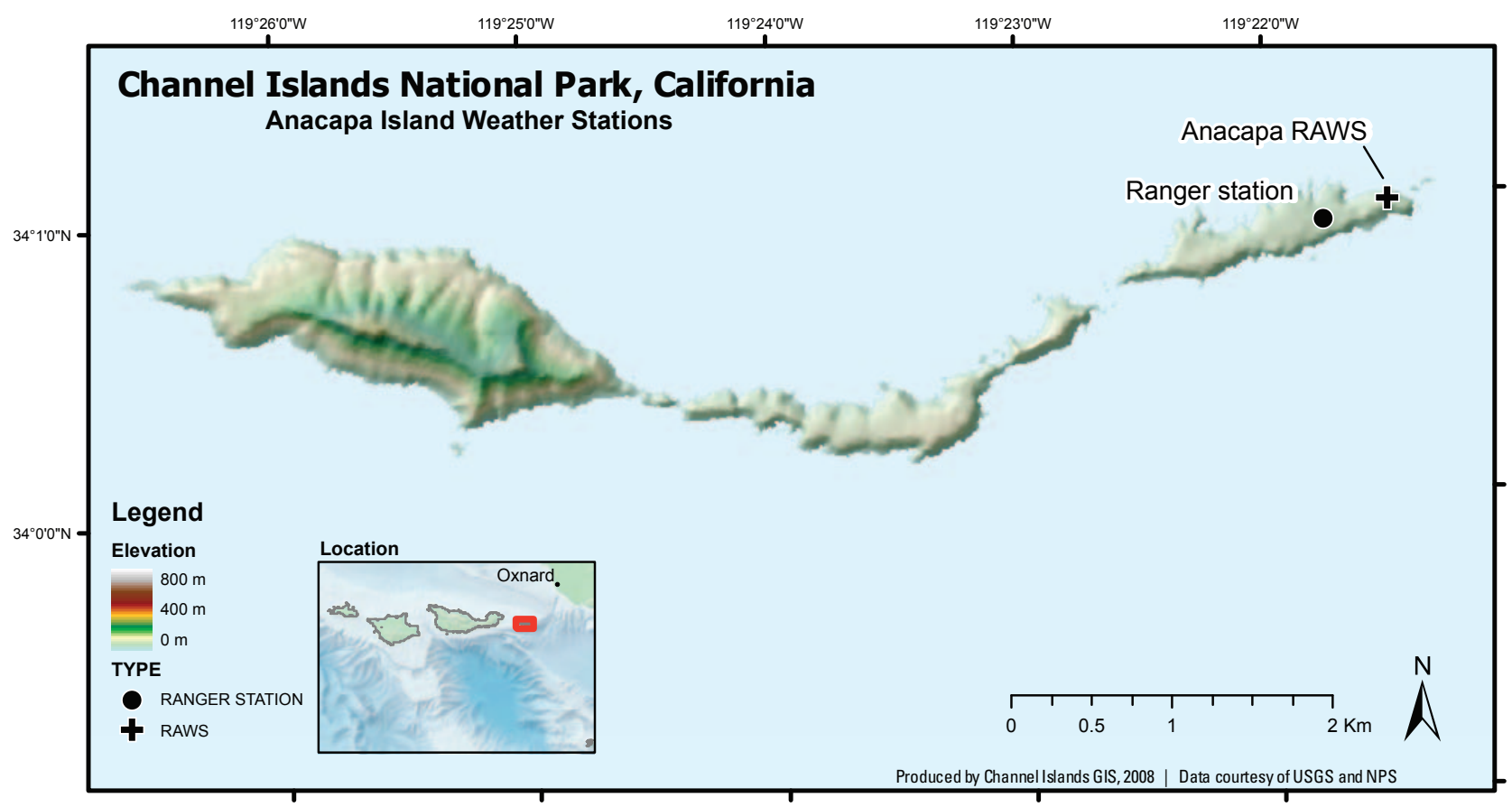

Figure 2. Location of the Remote Automated Weather Stations (RAWS) and Ranger Weather Station on Anacapa Island, Channel Island National Park, California. 


\section{Ranger Weather Station}

Between 1992 and 2000, a standard white wooden Forest Service type weather station was used for collection of weather observations by island staff. It had open-air slatted sides approximately $1.5 \mathrm{~m}(5 \mathrm{ft})$ off the ground and was located a few feet from the northeast corner of the Ranger's residence. In 1997, the residence basement floor cracked, requiring construction of a new foundation. As a result, the instrument housing was moved several feet northeast, to a location half-way between the Ranger's and the Maintenance Manager's residences (T. Gottshall, Channel Islands National Park, oral commun., 2005). A simple mercury maximumminimum ( $\mathrm{max} / \mathrm{min}$ ) thermometer with a magnet reset was used in the shelter, and there was no relative humidity instrument. Ocean water temperature was taken at the landing cove dock each morning using a thermometer that was hung from a string at a depth of about $1.5 \mathrm{~m}(5 \mathrm{ft})$ below the water surface (T. Gottshall, Channel Islands National Park, oral commun., 2005).

Before 1997, the anemometer was on top of the communications tower on the northeast corner of the Ranger's residence. Because construction of the residence foundation destabilized the tower, the anemometer was moved to the chimney of the residence where it could be easily reached. Data cables were fed into the house so that wind speed could be read indoors. A standard 8-inch copper rain gauge has been in place since 1997; it is located where the residence walkway meets the road (T. Gottshall, Channel Islands National Park, oral commun., 2005).

In 2007, a new shelter was installed about $1.5 \mathrm{~m}$ (5 ft) north of the rain gauge, near the junction of the Ranger residence walkway and the road. This distance prevents obstruction of wind flow between the shelter and the rain gauge. The shelter houses a max/min thermometer and an electronic temperature and relative humidity logger. The logger data is downloaded periodically and archived at the WRCC (Channel Islands National Park Ranger Weather Station Field Handbook). Maximum and minimum temperatures, current air temperature, relative humidity, precipitation, wind speed, wind direction, and horizontal visibility are reported each morning to Park Dispatch by island staff (Appendix B). These data are archived at Channel Islands National Park headquarters.

\subsection{Santa Cruz Island Overview}

Channel Islands National Park installed a RAWS on Santa Cruz Island in 1990 (fig. 3). It is located on the slope above the Main Ranch house in the Central Valley on The Nature Conservancy property. Additionally, there are five RAWS owned and maintained by CSUN (Boyle and Laughrin, 1999) and one RAWS owned and operated by the Santa Barbara Amateur Radio Club on Diablo Peak. The University of California, Santa Barbara, operates remote weather stations at several locations on the island for research purposes (C. Still, University of California Santa Barbara Department of Geography, written commun., 2007). These stations are not part of the NPS network, although they may provide important data over the short-term of record.

The Park maintains two Ranger Stations for weather data collection on Santa Cruz Island, one at the Scorpion Anchorage employee housing and the second at the U.S. Navy site on the isthmus. Additionally, precipitation data have been recorded at the Main Ranch from 1904 to the present; the data

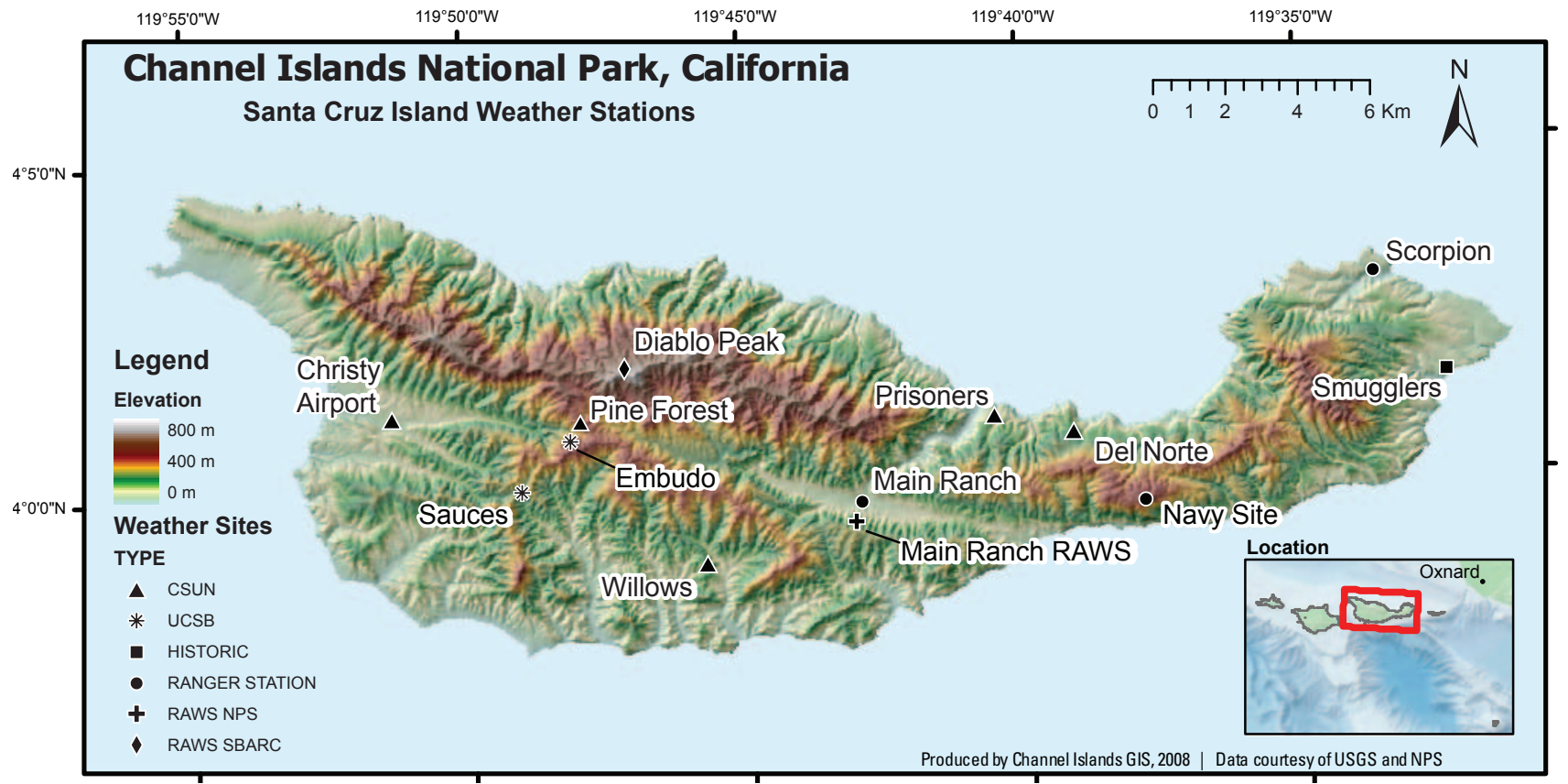

Figure 3. Location of seven Remote Automated Weather Stations (RAWS) and two Ranger Weather Stations on Santa Cruz Island, Channel Island National Park, California. 
are maintained by the University of California, Santa Cruz Island Reserve (L. Laughrin, Director, University of California Santa Cruz Island Reserve, oral commun., 2006).

\section{National Park Service Remote Automated Weather Station - Main Ranch}

The RAWS at the Main Ranch is maintained by National Park Service personnel. The station was originally installed in April 1990 at La Centinella (approximately 366 m (1,200 ft) elevation), but was moved out of that uncommonly cold valley in October 1994 to a more representative locale on a hill above the Main Ranch (122 m (400 ft) elevation) at latitude $33^{\circ} 59^{\prime} 45^{\prime \prime}$, longitude $119^{\circ} 43^{\prime} 20^{\prime \prime}$. This station is equipped with a Handar 555. Sensors include temperature, relative humidity, wind speed, wind direction, precipitation, and solar radiation. The weather station is solar powered but has an auxiliary battery. Data are transmitted through a GOES antenna to a satellite, where they are downloaded and posted on the WRCC website, in cooperation with NIFC. The data are recorded at 10-minute intervals and summarized by hour on the website. Weather station sensors are replaced two times per year and cables annually. For a complete description of software and sensors on the Santa Cruz Island-Main Ranch Station see Appendix A.

\section{Weather Stations Operated by Others}

Several organizations operate additional weather stations on Santa Cruz Island to fill research and recreational needs. Although not maintained by Channel Islands National Park, these data are available on request from these organizations, and they extend the Park's program with valuable weather observations from other locations on Santa Cruz Island.

\section{California State University, Northridge}

CSUN owns and maintains five weather stations on Santa Cruz Island. The stations were installed between 1995 and 1999 (fig. 3, table 1). They all are equipped with Campbell Scientific data loggers with the exception of Del Norte, which is equipped with a Handar 555. The Del Norte station is of particular interest because the data are archived and reported by the WRCC, along with the Channel Islands National Park data for Santa Cruz Island. The equipment is identical to the Main Ranch RAWS, except that solar radiation is not recorded

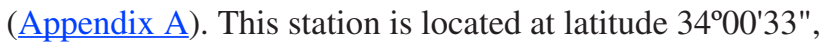
longitude $119^{\circ} 39^{\prime} 15^{\prime \prime}$, at an elevation of $244 \mathrm{~m}(800 \mathrm{ft})$ above mean sea level on a nearshore marine terrace approximately 2 kilometers (1.5 miles) east of the pier at Prisoners Harbor.

\section{Santa Barbara Amateur Radio Club - Diablo Peak}

The Santa Barbara Amateur Radio Club, Inc. (SBARC) funded and installed a RAWS on Diablo Peak at an elevation of $742 \mathrm{~m}$ ( 2,434 ft) above mean sea level on 15 January 2004 as a public service. The Santa Barbara Amateur Radio Club is a non-profit 501(c) 3 charitable and educational corporation founded in 1920 (B. Talanian, Santa Barbara Amateur Radio Club, written commun., 2005). The weather station monitors and reports data to the mainland every 5 minutes via VHF radio. The data are collected by the Civilian Weather Observer Program (CWOP). The station reports wind speed, wind direction, temperature, barometric pressure, humidity, dew point, and precipitation. A full description of this weather system data is explained on links at the following webpage: http://www.met.utah.edu/cgi-bin/roman/meso base. cgi?stn=AR320.

Table 1. Automated Remote Weather Stations operated by other agencies or organizations on Santa Cruz Island and San Miguel Islands, Channel Islands National Park, California.

[SBARC, Santa Barbara Amateur Radio Club; CSUN, California State University, Northridge; UCSB, University of California, Santa Barbara]

\begin{tabular}{|c|c|c|c|c|c|}
\hline Site & $\begin{array}{c}\text { Location } \\
\text { (latitude/longitude) }\end{array}$ & Data logger & $\begin{array}{c}\text { Elevation, } \\
\text { in meters (feet) } \\
\text { above mean } \\
\text { sea level }\end{array}$ & Period of record & Operator \\
\hline Santa Cruz Prisoners & $34^{\circ} 00^{\prime} 59^{\prime \prime} \mathrm{N} / 119^{\circ} 40^{\prime} 37^{\prime \prime} \mathrm{W}$ & Campbell Scientific CR10X & $126(414)$ & June 1995-present & CSUN \\
\hline Santa Cruz Christy Airport & $34^{\circ} 01^{\prime} 04^{\prime \prime} \mathrm{N} / 119^{\circ} 51^{\prime} 21^{\prime \prime} \mathrm{W}$ & Campbell Scientific CR10X & $63(208)$ & Dec. 1996-present & CSUN \\
\hline Santa Cruz Pine Forest & $34^{\circ} 00^{\prime} 46^{\prime \prime} \mathrm{N} / 119^{\circ} 48^{\prime} 07^{\prime \prime} \mathrm{W}$ & Campbell Scientific CR10X & $442(1,450)$ & Dec. 1996-present & CSUN \\
\hline Santa Cruz Del Norte ${ }^{1}$ & $34^{\circ} 00^{\prime} 33^{\prime \prime} \mathrm{N} / 119^{\circ} 39^{\prime} 15^{\prime \prime} \mathrm{W}$ & Handar 555 & $244(800)$ & Dec. 1999-present & CSUN \\
\hline San Miguel Navy & $34^{\circ} 01^{\prime} 58^{\prime \prime} \mathrm{N} / 120^{\circ} 21^{\prime} 51^{\prime \prime} \mathrm{W}$ & Handar 555 & $255(835)$ & intermittent & U.S. Navy \\
\hline Santa Cruz Sauces & $34^{\circ} 0^{\prime} 3.88^{\prime \prime} \mathrm{N} / 119^{\circ} 49^{\prime} 4.48^{\prime \prime} \mathrm{W}$ & Campbell Scientific & $290(951)$ & Dec. 2003-present & UCSB \\
\hline Santa Cruz Embudo & $34^{\circ} 0^{\prime} 47.20^{\prime \prime} \mathrm{N} / 119^{\circ} 48^{\prime} 11.12^{\prime \prime} \mathrm{W}$ & Campbell Scientific & $420(1,378)$ & Sept. 2005-present & UCSB \\
\hline
\end{tabular}

${ }^{1}$ Santa Cruz Island Del Norte station is owned and maintained by CSUN, but the data are collected and archived by Western Regional Climate Center. This station is part of the Remote Automated Weather Station (RAWS) program. 
The SBARC weather system equipment is manufactured by Peet Bros and is a low-end system costing less than $\$ 1,000$. Systems of this type are not tested annually for precision or accuracy. There is no periodic method or instruction by the manufacturer to perform calibration of any sensors as there is with the high-end systems operated by the National Weather Service (NWS). However, this type of system has improved immensely in the past several years because of refinements in miniature sensor accuracy and micro-processors. The readings from thousands of similar stations provide specific readings in micro climates not otherwise covered by the National Weather Service (B. Talanian, Santa Barbara Amateur Radio Club, written commun., 2005).

\section{University of California, Santa Barbara}

The University of California, Santa Barbara, operates two Campbell Scientific weather stations on Santa Cruz Island associated with fog and climate research conducted by Dr. Christopher Still in the Department of Geography (C. Still, University of California, Santa Barbara Department of Geography, written commun., 2007). The Sauces station was installed in December 2003. It logs the following measurements at 15-minute intervals: air temperature and relative humidity inside and outside the adjacent Bishop pine canopy, dewpoint temperature, photosynthetically active radiation (PAR, 400-700 nanometer (nm) wavelengths), solar radiation $(400-111 \mathrm{~nm})$, wind speed and direction, and vertical precipitation (rain) and horizontal precipitation (fog). These measurements are supplemented with numerous measurements of soil moisture and temperature at multiple depths beneath the pine canopy and beneath an adjacent grassy area. Both relative humidity and temperature sensors (Vaisala HMP45C) are calibrated annually by Campbell Scientific. The weather station is solar powered and has an auxiliary battery. The data are archived on a Campbell CR10x datalogger and downloaded several times a year by members of the Still Laboratory (table 1). This station is located at latitude $34^{\circ} 0^{\prime} 3.88^{\prime \prime} \mathrm{N}$ and longitude $119^{\circ} 49^{\prime} 4.48^{\prime \prime} \mathrm{W}$ at an elevation of $290 \mathrm{~m}$ (951 ft) above mean sea level.

The upper Embudo Canyon station was installed in September 2005. The following measurements are logged at 15-minute intervals: air temperature and relative humidity, dewpoint temperature, photosynthetically active radiation (PAR), solar radiation (400-111 nm), net radiation (net of downwelling and upwelling radiation from 0-100 um wavelengths), wind speed and direction, vertical precipitation (rain), and horizontal precipitation (fog). The relative humidity and temperature sensor (Vaisala HMP-45C) is calibrated annually by Campbell Scientific. The weather station is solar powered and has an auxiliary battery. The data are archived on a Campbell CR1000 datalogger and downloaded several times a year by members of the Still Laboratory. This site also has a webcam accessible through the Santa Barbara Amateur Radio
Club, with on-line data access to the datalogger via the Club's wireless connections to the mainland. This station is located at latitude $34^{\circ} 0^{\prime} 47.20^{\prime \prime} \mathrm{N}$ and longitude $119^{\circ} 48^{\prime} 11.12^{\prime \prime} \mathrm{W}$ at an elevation of $420 \mathrm{~m}(1,378 \mathrm{ft})$ above mean sea level.

\section{Ranger Weather Stations}

Weather data are collected and reported daily to Park Dispatch by Channel Islands National Park staff at two locations on Santa Cruz Island: at the Scorpion housing complex on the east end of the island and at the U.S. Navy site on the isthmus (ppendix B).

\section{Scorpion}

A standard Forest Service type instrument shelter with non-standard temperature and humidity equipment was used to collect weather observations at the NPS Scorpion housing complex beginning in 2002. Upgraded weather equipment including a max/min thermometer, a relative humidity and temperature logger, and a precipitation gauge were installed there in February 2006 (ㄹppendix B).

\section{Navy Site}

From 2002 until 2007, a Davis Vantage PRO all-in-one wireless digital readout display was the primary source for Ranger Weather Station information at the U.S. Navy site. The sensors were mounted on the roof of an outbuilding upslope from employee housing. The unit displayed temperature (inside, outside), humidity (inside, outside), wind chill, barometric pressure, and precipitation. In 2007, the Davis Vantage PRO was replaced with a standard Forest Service type shelter located near the north parking lot of the Navy site housing. The shelter houses a max/min thermometer, an electronic temperature and humidity logger, and instruments similar to those on Anacapa Island. The logger data are periodically downloaded and archived at the WRCC.

\section{Main Ranch Precipitation Data}

Currently, the Director of the Santa Cruz Island Reserve, part of the University of California Natural Reserve System, collects precipitation and $\mathrm{max} / \mathrm{min}$ temperature data in the Central Valley. These data have been collected at the Reserve Director's house approximately 1.0 kilometers ( 0.62 miles) west of the Main Ranch from 1976 to the present. This extends the historic record for the Central Valley from 1903 to the present. Precipitation data collected in the Central Valley are archived with the Weather and Climate Monitoring Program data files on the Channel Islands National Park computer network. 


\subsection{Santa Rosa Island Overview}

The Channel Islands National Park maintains one RAWS and one Ranger Weather Station on Santa Rosa Island (fig. 4). The Ranger Weather Station has been moved several times since NPS acquired the island in 1987. Data are no longer collected at past Ranger Weather Station locations.

\section{National Park Service Remote Automated Weather Station-Black Mountain}

The Santa Rosa Island RAWS was installed on Black Mountain in April 1990 at 396 m (1,298 ft) elevation, latitude $33^{\circ} 58^{\prime} 40^{\prime \prime}$, longitude $120^{\circ} 04^{\prime} 40$. The weather station is solar powered and has an auxiliary battery. The system is a Handar 555. Sensors include air temperature, relative humidity, wind speed, wind direction, precipitation, solar radiation, and fuel moisture/fuel temperature. The sensors and cables are replaced annually. Data are transmitted through a GOES antenna to a satellite, where they are downloaded and posted on the WRCC website, in cooperation with NIFC. The data are recorded at 10-minute intervals and summarized by hour on the website. For a complete description of system and sensors, see Appendix A.

\section{Ranger Weather Station}

Ranger Weather Station observations were collected from April 1987 through January 1992 at the historic NPS housing at Johnson's Lee located on the south side of the island (fig. 4). This station was equipped with a max/min thermometer; a battery powered digital wind speed instrument, a relative humidity sling psychrometer, and a standard rain gauge. In January 1992, the Park employee housing was moved to Bechers Bay where an instrument shelter and rain gauge were installed. In fall of 1998, the instruments were moved to the new Park employee housing on the bluff between Windmill and Cherry Canyons (M. Senning, Channel Islands National Park, written commun., 2000). The shelter and instruments, but not the rain gauge, were destroyed by high winds in 2002 . From 2002 until 2007, island staff used a hand-held device that measured temperature, relative humidity, barometric pressure, and wind speed (M. Senning, Channel Islands National Park, oral commun. 2006). A small weather station housing a $\mathrm{max} / \mathrm{min}$ thermometer and an electronic temperature and relative humidity logger was installed in 2007. The logger data are downloaded periodically and archived at the WRCC (Channel Islands National Park Ranger Weather Station Field Handbook). Maximum and minimum temperatures, current air temperature, relative humidity, precipitation, wind speed, wind direction, and horizontal visibility are reported each morning to Park Dispatch by island staff (Appendix B $)$. These data are archived at Channel Islands National Park headquarters and reported on the WRCC web site.

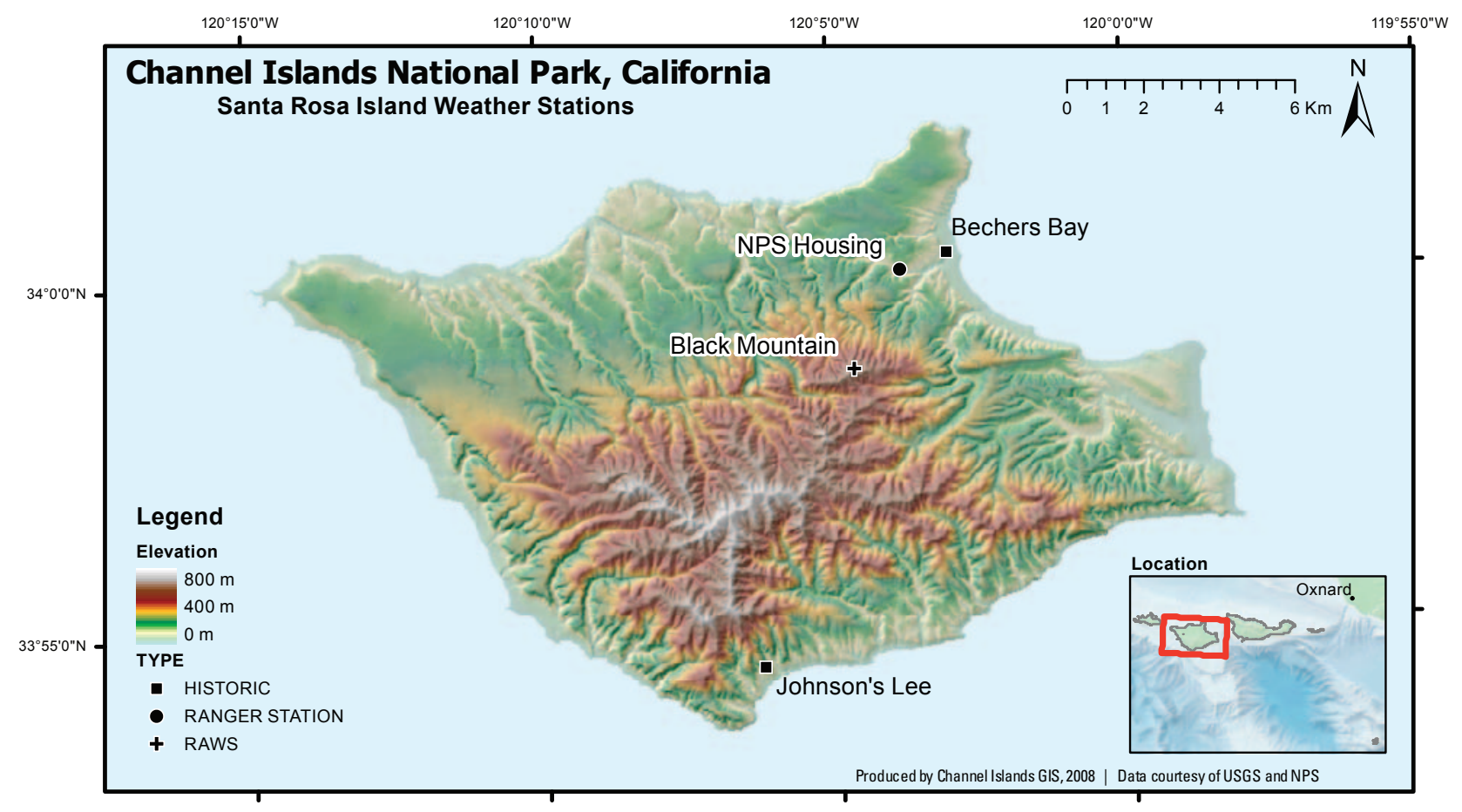

Figure 4. Location of one Remote Automated Weather Station (RAWS) and current and historic Ranger Weather Stations on Santa Rosa Island, Channel Island National Park, California. 


\subsection{Santa Barbara Island Overview}

Channel Islands National Park operates one RAWS and one Ranger Weather Station on Santa Barbara Island (fig. 5). Data were not collected on the island historically.

\section{National Park Service Remote Automated Weather Station}

The Santa Barbara Island RAWS was installed in April 1995 at Arch Point, elevation $54 \mathrm{~m}(176 \mathrm{ft})$ above mean sea level, latitude $33^{\circ} 29^{\prime} 00^{\prime \prime}$, longitude $119^{\circ} 02^{\prime} 00^{\prime \prime}$. The station is equipped with a Handar 555. Sensors include air temperature, relative humidity, precipitation gauge, wind speed, wind direction, and solar radiation. The system is solar powered and has an auxiliary battery; sensors must be swapped two times per year. Data are transmitted via satellite to the WRCC and posted on the Internet. In June 1998, the station was transported to the mainland for servicing and returned to Santa Barbara Island. See Appendix A for details on the system and sensors.

\section{Ranger Weather Station}

A rain gauge and a thermometer were installed on Santa Barbara Island in 1992 when a shop and house were constructed near Landing Cove. They were installed on a post between the shop and employee housing. The weather equipment was upgraded in 2007 with an air temperature sensor, a maximum-minimum thermometer, and relative humidity data logger housed near the residence in a small U.S. Forest Service type instrument shelter identical to other island Ranger Weather Stations. The older rain gauge was replaced in its original location with a new, standard rain gauge. Maximum and minimum temperatures, current air temperature, relative humidity, precipitation, wind speed, wind direction, and horizontal visibility are reported to Park Dispatch when Park personnel are present on the island. These data are archived at Channel Islands National Park headquarters and reported on the WRCC web site.

\subsection{San Miguel Island Overview}

The most reliable weather data for San Miguel comes from Ranger Weather Station observations. There have been several remote stations on the island since the early 1990s (fig. 6), but they have not been maintained, and the automated record has been inconsistent through time.

\section{National Park Service Remote Automated Weather Station}

In 1997, the NPS installed a Met One weather data logger and instruments. The station was placed near wind generators south of the current Ranger Station. The station functioned properly for a brief period, but individual component failures resulted in inconsistent data. Funds were not available to maintain the station and it was eventually removed.

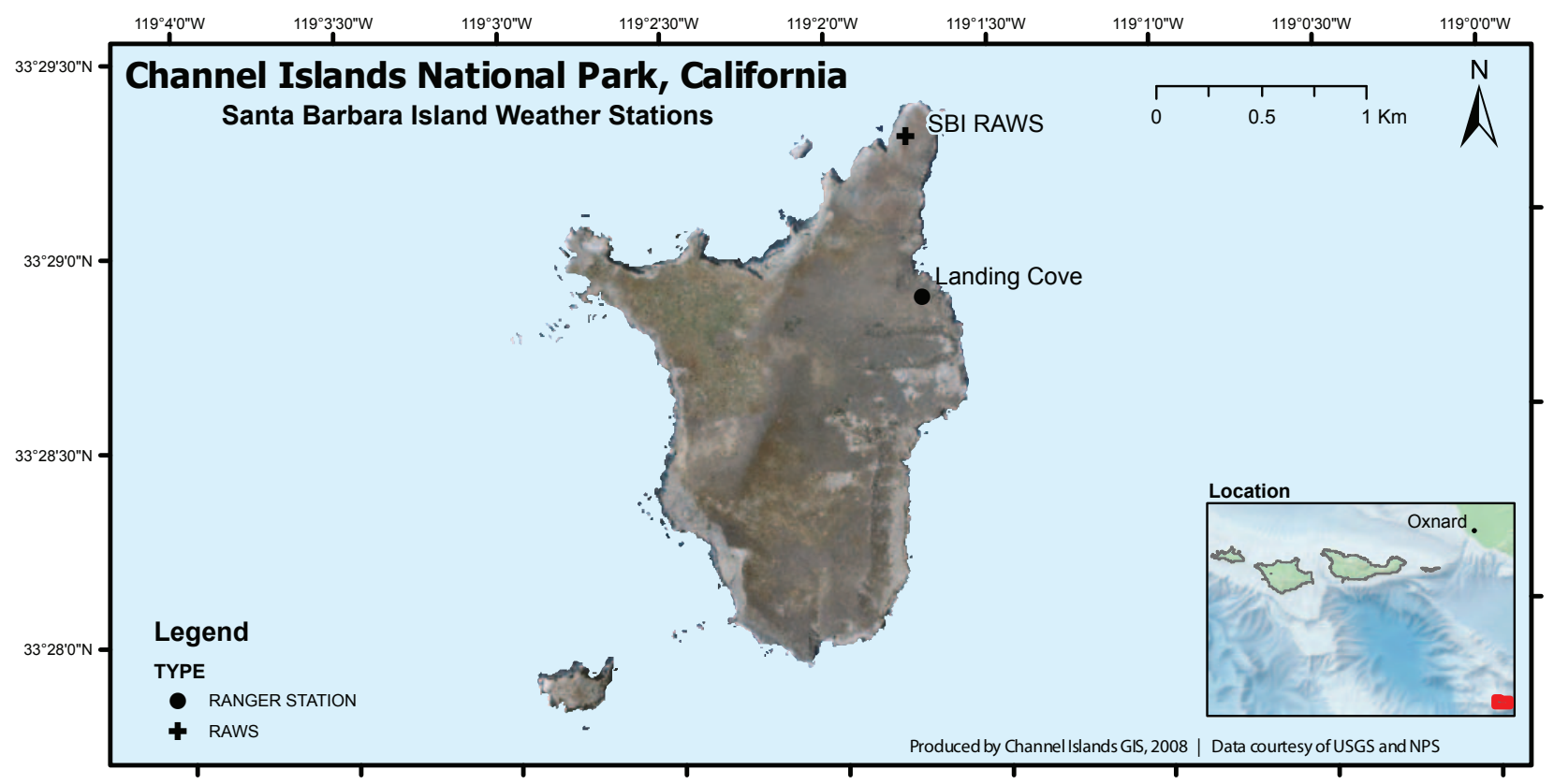

Figure 5. Location of one Remote Automated Weather Station (RAWS) and a Ranger Weather Station on Santa Barbara Island, Channel Islands National Park, California. 


\section{Remote Automated Weather Station Operated by the Navy}

The U.S. Navy RAWS is located on San Miguel Hill, elevation $253 \mathrm{~m}(831 \mathrm{ft})$ above mean sea level, the highest point on the island. The current structure replaced a white metal tower. The abandoned tower was removed by the Island Ranger in 1992, the same year the U.S. Navy removed the 4,000-pound radioactive nuclear generator that powered the station. The station is now powered by two solar panels and runs a Handar 555B datalogger. The power supply at this station is one of the most common causes for station failure. Maintenance by the Navy and performance of this station has been inconsistent.

\section{Ranger Weather Station}

Weather observations have been recorded at four different locations on San Miguel Island over the years. The National Weather Service in Los Angeles hired Herbert Lester, former island ranch manager, to record and radio weather information to Santa Barbara, California, twice a day. He did this from the mid-1930s until the outbreak of World War II; these data are not available to the Park. Rangers and other Park staff have been collecting morning weather observations on San Miguel for the past several decades, but there are gaps in the data because the island is not always staffed.

Weather data were collected at the Ranger Weather Station in Nidever Canyon from 1977 until February of 1997. At that point, the station was moved to its present location near an airstrip. Early in the period of record, vibration from the wind would cause the min/max needles to creep downward, understating the readings. In October 1994, the San Miguel Island Ranger moved the thermometer to a more solid surface on the retaining wall in front of the station. At the time, the rain gauge was moved farther away from the roofline to prevent shadowing. Since 1994, temperature data at the Ranger Weather Station have been collected nearly continuously using a HOBO temperature logger provided by the Channel Islands National Park Kelp Forest Monitoring Program.

A new station housing and equipment were installed between the Ranger residence and the wind generators in 2007 (Appendix B). Particular care was taken to ensure that the shelter could withstand vibrations from high winds. Equipment was standardized with that on the other islands, and includes a maximum-minimum thermometer, a temperature and relative humidity data recorder, and standard rain gauge.

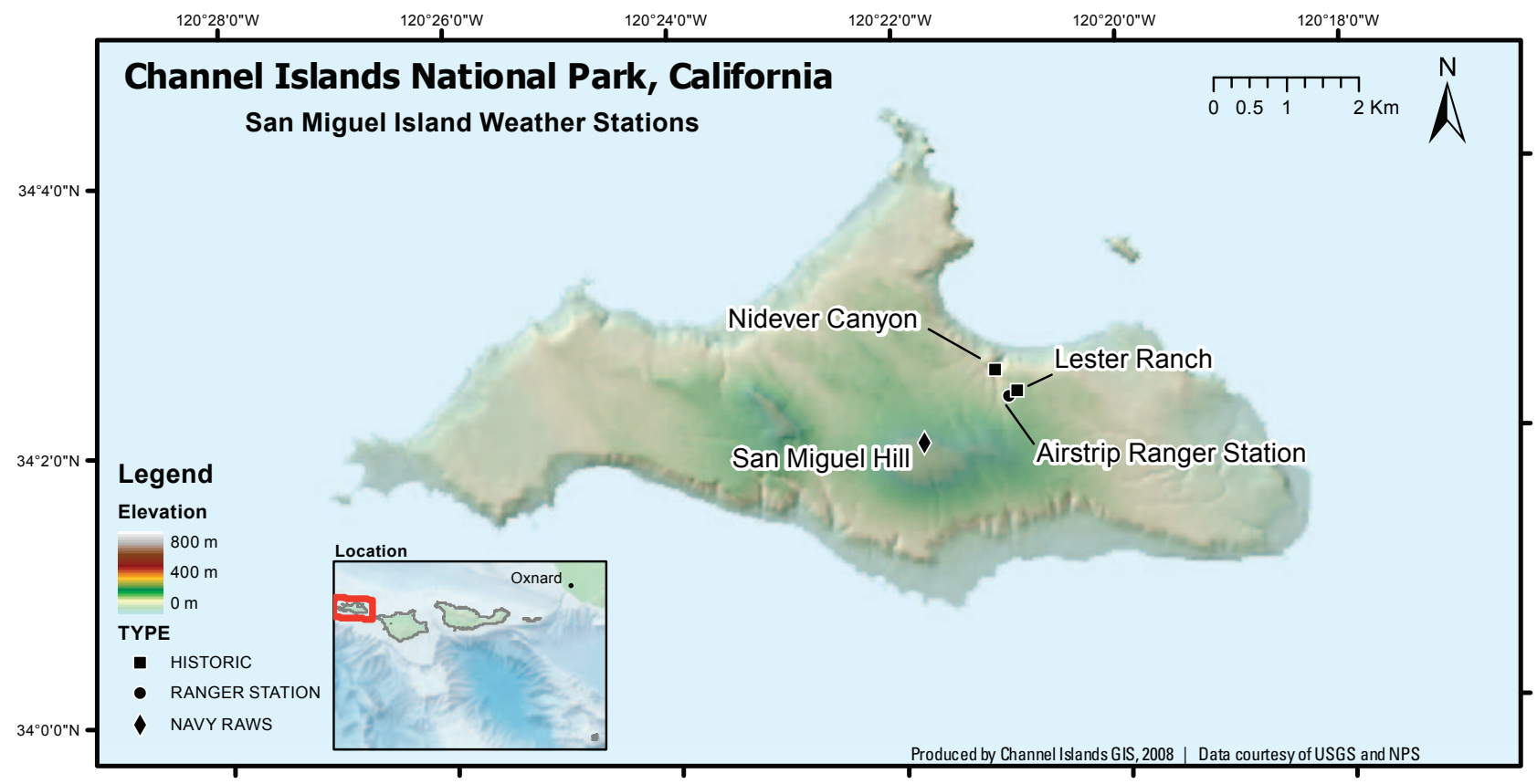

Figure 6. Location of a Remote Automated Weather Station (RAWS) and a Ranger Weather Station on San Miguel Island, Channel Islands National Park, California. 


\subsection{Weather Station Maintenance and Diagnostics}

\subsection{Remote Automated Weather Station (RAWS) Maintenance}

The Channel Islands National Park Remote Automated Weather Station Field Handbook describes station maintenance requirements, provides equipment operating schematics and instructions, and gives manufacturer technical support contacts. This Handbook is maintained as a reference available on request from the Weather Program Manager at Channel Islands National Park; it is updated with new technical information on an as-needed basis.

The National Park Service RAWS weather stations for Anacapa Island, Santa Barbara Island, Santa Cruz Island Main Ranch, and Santa Rosa Island are maintained annually through a national RAWS Maintenance Depot Contract with the Bureau of Land Management (BLM) at NIFC in Boise, Idaho. The Depot Contract allows the Park to exchange RAWS equipment and sensors with the Depot for a flat rate. Used parts are repaired and calibrated for return to the field on a rotating basis among RAWS nationwide. Sensors are replaced once per year; cables, tipping bucket, solar panel, auxiliary battery, and the barometric pressure senor are replaced on an as-needed basis. The Data Collection Platform (DCP) is replaced approximately every 5 years or when needed. After weather station parts are replaced, the used parts should be returned promptly to NIFC.

The Depot services stations nationwide and requires a quick turn-around of parts from the field, especially during the fire season. A 30-day turnaround is generally acceptable for weather station parts. Normally sensors are received from the Depot within 3 to 5 days of a request. Detailed instructions for Ordering and Returning Weather Station Parts are presented in the RAWS Field Handbook.

The Annual Preventative Maintenance Checklist provided in the RAWS Field Handbook should be followed for each island RAWS. Maintenance should be scheduled to accommodate field schedules and to avoid predictably bad weather. April/May and October/November are good months for maintenance. RAWS maintenance records are archived in paper form with the Channel Islands National Park Weather Program Manager as maintenance is performed.

\subsection{Ranger Weather Station Instrument Maintenance}

The Channel Islands National Park Ranger Weather Station Field Handbook includes detailed instructions for data downloads and equipment and shelter maintenance. The Handbook includes Standard Operating Procedures (SOPs) for each piece of equipment, along with excerpts from manufacturer's manuals, web-site information, and contacts for equipment operation and calibration. This Handbook is maintained as a reference available on request from the Weather Program Manager at Channel Islands National Park; it is updated with new technical information on an as-needed basis. The Ranger Weather Station maintenance records are written on paper forms as maintenance is performed, as are the RAWS maintenance records. These records are kept in looseleaf notebooks, organized by year, at the desk of the Channel Islands National Park Weather Program Manager.

\subsection{Weather and Climate Monitoring Program Tasks and Roles}

The Channel Islands National Park Weather and Climate Monitoring Program requires cooperative effort among many partners. It is somewhat atypical of weather monitoring programs at mainland sites because stations are spread across five islands with individual staff and limited access. Thus, it is not efficient for a core staff of technicians to service all the stations. Instead, island and mainland personnel, cooperators, and contractors are tasked with various aspects of station maintenance, data handling, reporting, and program coordination. The Weather and Climate Monitoring Program is administered by a Weather Program Manager located on the mainland, who coordinates with a multitude of partners to ensure that the stations are maintained and that the data are collected and reported consistently. Partners and their roles and responsibilities are listed below.

- Island staff, including Park Rangers and others on site, verbally report weather observations to Park Dispatch each morning during Morning Report. They also record the weather observations on National Oceanic and Atmospheric Administration (NOAA) "Form 72-5: A Marine Coastal Weather Log - Coastal Station". A copy of the Log is filed at the Ranger Weather Station; the original is brought to the mainland monthly.

- Park Dispatch records the daily observations during Morning Report when island staff reports weather conditions and makes the observations available to others needing daily weather for boating and other operations.

- The Natural Resources Management Division Administrative Assistant collects the monthly Ranger Weather Station observation logs, archives a copy, and forwards them to the WRCC in Reno, Nevada, for offsite archival.

- WRCC staff enters the Ranger Weather Station temperature and precipitation data and posts it to their website. 
- The Weather Program Manager coordinates the efforts of Island staff, cooperating researchers from other agencies, and Mediterranean Coast Network Fire Management Program staff for RAWS parts replacement for specific stations on the required replacement schedule.

- The Weather Program Manager manages parts swaps under the Depot Contract with BLM and NIFC, including coordinating and overseeing the parts order, field replacement, and return shipment for each RAWS.

- WRCC receives the RAWS data feed via satellite, conducts automated quality assurance and qualitycontrol data checks, and posts the data to their website.

- The Program Manager, Island staff, and WRCC staff inspect the data display hosted by WRCC daily to look for missing data or apparent errors that may indicate equipment failure.

- Island staff work with the Program Manager to troubleshoot and repair equipment malfunctions.

- The Channel Islands National Park database manager, a private consultant, and WRCC staff assist with data handling, quality control and quality assurance, and reporting.

- The Weather Program Manager conducts program oversight, protocol and Handbook review and program outreach.
- The Weather Program Manager maintains RAWS and Ranger Weather Station maintenance and replacement records in a loose-leaf notebook continuously as maintenance is performed.

- The Weather Program Manager updates and revises the Field Handbooks and the Weather Protocol document as needed.

- The Weather Program Manager downloads and archives the RAWS and Ranger Weather Station data on a local network periodically.

\subsection{Reporting}

Weather data are collected and reported continuously, unlike other Channel Islands National Park monitoring programs. Therefore, a traditional "annual report" summarizing the data is not prepared as part of the program. Instead, users are able to access and download data and site metadata from the WRCC website (table 2) at any time for summarization over the period of interest to them. Metadata on RAWS and Ranger Weather Station parts replacements, repairs, and upgrades are likewise kept as they occur as a continuous record. Maintenance records are kept in hard copy binders by the Program Manager at Channel Islands National Park.

Table 2. Websites with data from Remote Automated Weather Stations located in Channel Islands National Park, California.

\begin{tabular}{|c|c|}
\hline Website & Description \\
\hline http://www.wrcc.dri.edu/channel isl & $\begin{array}{l}\text { Maintained by the Western Regional Climate Center (WRCC), this } \\
\text { website displays data from the Channel Islands Remote Automated } \\
\text { Weather Stations (RAWS). Ranger weather data is also stored on this } \\
\text { site. See SOP\#16 in the Field Handbook for Ranger Station Weather } \\
\text { Data Collection for instructions on accessing this website. }\end{array}$ \\
\hline http://www.csun.edu/ hfgeg010/santacruz.html & California State University, Northridge (CSUN) weather data. \\
\hline http://www.met.utah.edu/cgi-bin/roman/meso_base.cgi?stn=AR320 & $\begin{array}{l}\text { Santa Barbara Amateur Radio Club, Inc. (SBARC) RAWS on Diablo } \\
\text { Peak. }\end{array}$ \\
\hline http://www.geog.ucsb.edu/ cstill & $\begin{array}{l}\text { This site is maintained by the Still Laboratory at the University of } \\
\text { California Santa Barbara; it describes the equipment used for fog } \\
\text { and climate research. }\end{array}$ \\
\hline
\end{tabular}




\subsection{Training Requirements}

The weather observations collected by Channel Islands National Park need to be made consistently and continuously through time. Otherwise, they will not be useful for short- or long-term weather and climate information needs. To ensure consistent data collection, it is essential that each individual participating in the program be trained in the maintenance and operation of the equipment they use. Additionally, all cooperators need to be aware of and trained in the routines for data recording, handling, archival, and retrieval. Finally, the Weather Program Manager needs to be experienced with coordination of multiple cooperators, trained in National Park Service contract management, and trained with the specific procedures for parts exchange with the BLM - NIFC RAWS equipment Depot. A list of training requirements and training sites is detailed in each of the Field Handbooks for RAWS and Ranger Weather Station operation. At a minimum, the following training is required for efficient program operation:

- RAWS certification through NIFC for all personnel calibrating, removing, and installing automated station parts;

- Manufacturer training via technical manuals and on-line website instructions for each of the pieces of equipment used at the island Ranger Weather Stations;

- Experience in accessing and retrieving weather data from the WRCC website for all cooperators participating in the Weather and Climate Monitoring Program;

- Training in Depot contract administration and BLM and NIFC programmatic expectations for the Weather Program Manager.

\subsection{Channel Islands National Park Weather Data Websites}

Several agencies acquire and display data from the island RAWS. The data are reported in various formats on their websites (table 2). The WRCC is the official contracted archive for NIFC data nationwide, including data for the National Park Service sites; therefore, the WRCC site should be used for archival of weather data from the RAWS and Ranger Weather Stations owned and operated by the Channel Islands National Park.

\subsection{Acknowledgments}

We thank the staff of Channel Islands National Park for their assistance with information on program history; Island Managers Ian Williams, Mark Senning, and Randy Nelson provided essential information on station history and other site metadata. Kelly Redmond and Greg McCurdy provided guidance on station siting and installation and data acquisition and handling procedures. Ian Williams, John Gross, Chris Peltz, Dessa Emch, Christpher Still, and Lyndal Laughrin provided valuable reviews of this document. Numerous Channel Islands staff have managed the Program over the years, including most recently Greg Austin, Catherin Schwemm, and Steve Ortega.

\subsection{References}

Boyle, T., and Laughrin, L., 1999, California's Santa Cruz Island Weather, in David R. Browne, ed., Proceedings of the Fifth California Islands Symposium, OCS Study MMS-99-0038: U.S. Department of the Interior, Minerals Management Service, Pacific OCS Region, Washington, D.C., p. 93-99.

Redmond, K., and McCurdy, G., 2005, Channel Islands National Park: Design considerations for weather and climate monitoring: Reno, Nevada, Western regional Climate Center Desert Research Institute, WRCC Report 05-02 July 2005, $111 \mathrm{p}$.

Richards, R., 1997, Channel Islands National Park meteorological data sources for research applications: Helena, Montana, R.G. Richards Engineering, Progress report to Channel Island National Park, 64 p.

Yoho, D., Boyle, T., and McIntire, E., 1999, The climate of the Channel Islands, California, in David R. Browne, ed., Proceedings of the Fifth California Islands Symposium, OCS Study MMS-99-0038: Washington, D.C., U.S. Department of the Interior, Minerals Management Service, Pacific OCS Region, P.. 81-88.

Williams, I., Dec. 2002, Brief summary of San Miguel Island weather history: Report submitted to Channel Islands National Park, Ventura, California, 10 p. 


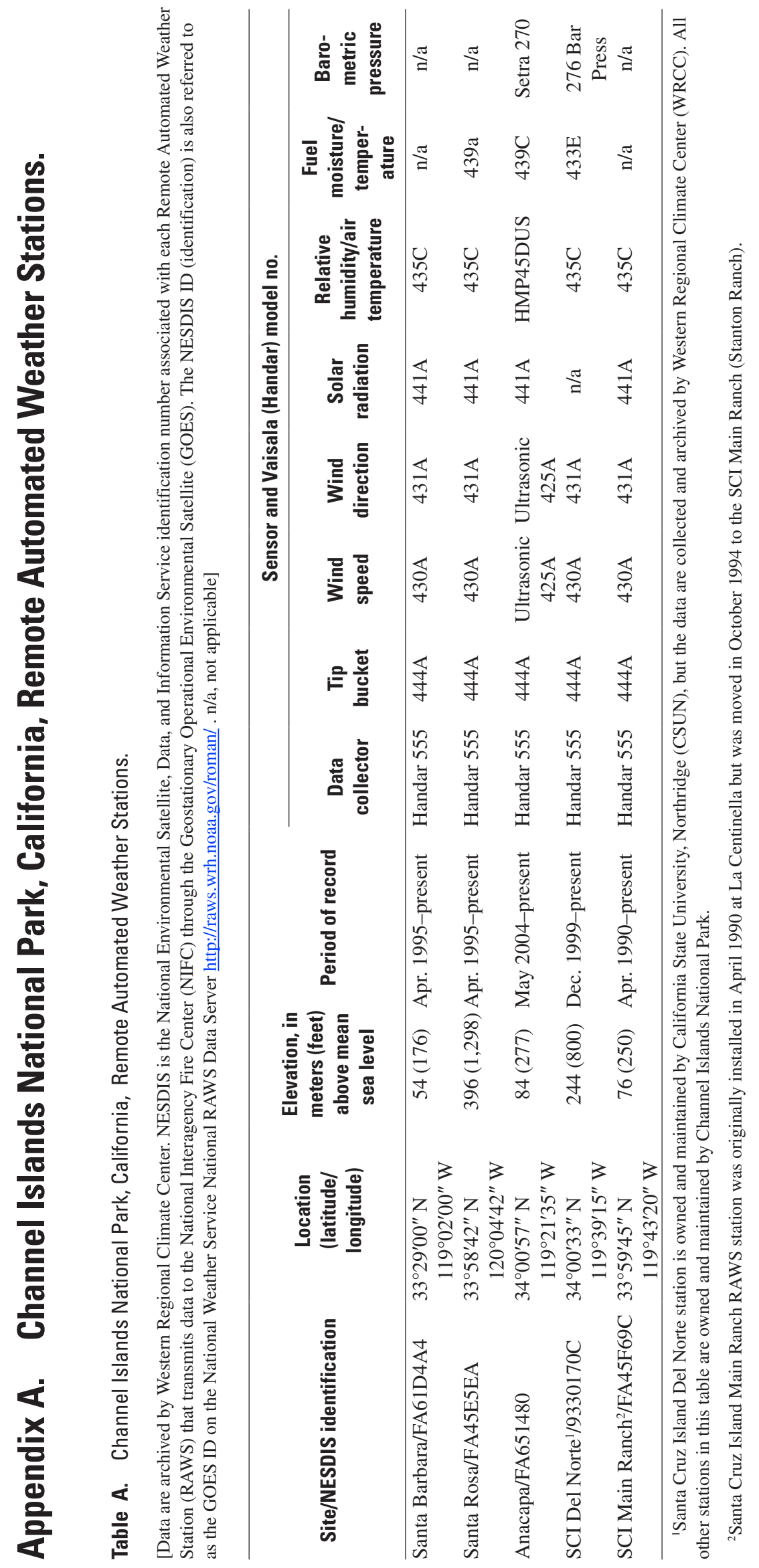



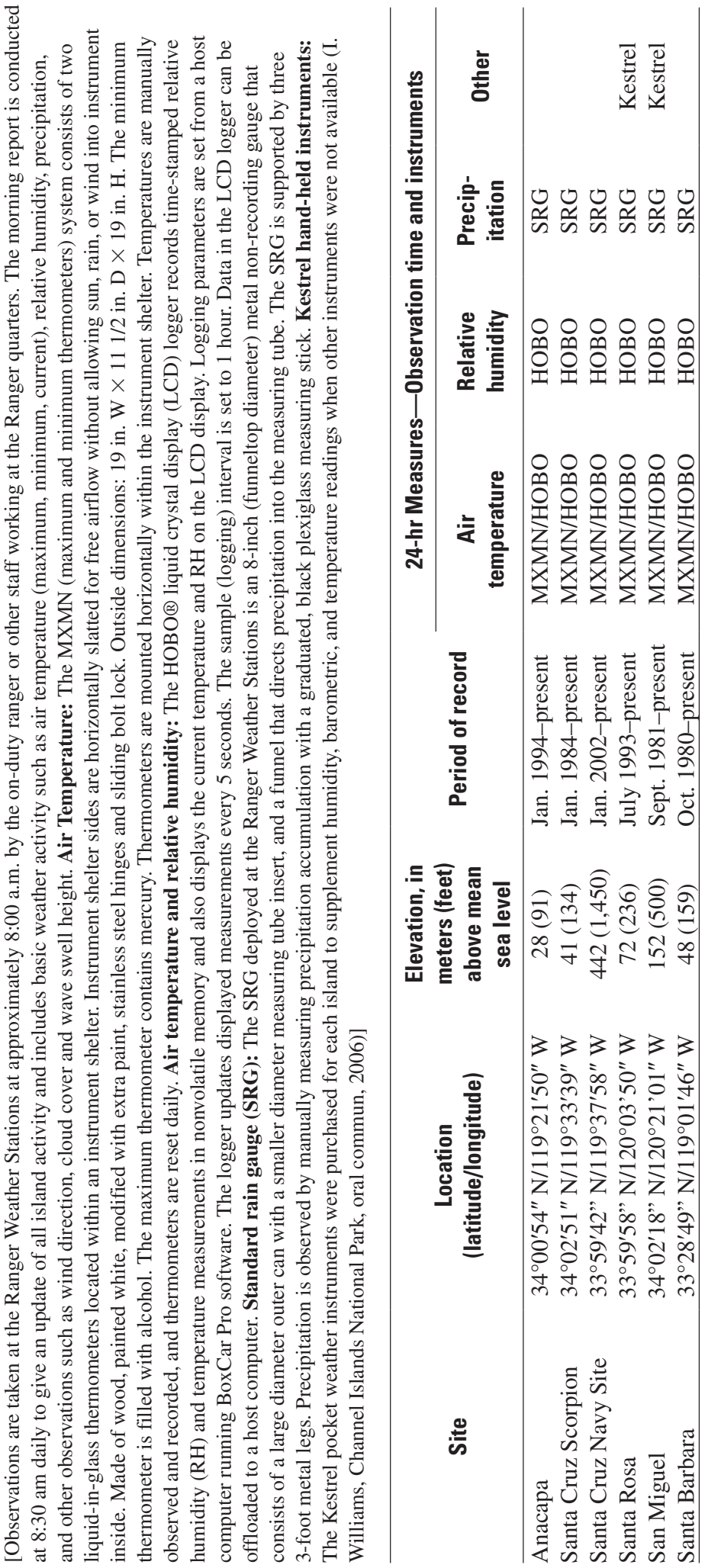
This page intentionally left blank. 
Manuscript approved for publication, July 30, 2008

Prepared by the USGS Publishing Network,

Publishing Service Center, Sacramento, California

Myrna DeBortoli

Yvonne Roque

Susan Davis

For more information concerning the research in this report, contact the Western Ecological Researach Center

3020 University Drive East, Modoc Hall

Sacramento, California 95619 


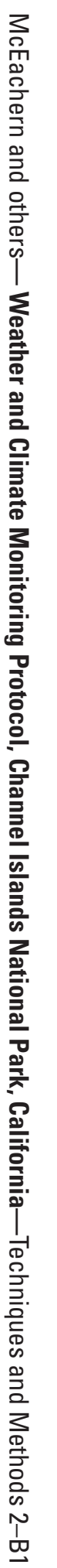

8 Printed on recycled paper 